\title{
LIBMAN-SACKS ENDOCARDITIS IN A SYSTEMIC LUPUS ERYTHEMATOSUS MALE PATIENT
}

\author{
Fauqa Arinil Aulia, Sidarti Soehita \\ Department of Clinical Pathology, Faculty of Medicine Airlangga University, Dr. Soetomo Hospital, Surabaya, Indonesia. \\ E-mail:fauqa.arinil.aulia@gmail.com
}

\begin{abstract}
Libman-Sacks endocarditis (verrucous vegetations, marantic, or nonbacterial thrombotic endocarditis) is a rare cardiac manifestation in Systemic Lupus Erythematosus (SLE). The objective was to describe Libman-Sacks endocarditis in an SLE male patient. A 21-year-old male was admitted to the hospital with shortness of breath, epigastric pain, oral ulcer, discoid lesions, and knee joint pain since three months before. He worked as a paper mill employee and was exposed to instruments radiating UV rays for two years. Antibiotics initiation was given due to an infective endocarditis suspicion. Vital signs were as follows: temperature $37^{\circ} \mathrm{C}$, heart rate 110 beats/minute, respiratory rate 30 breaths/minute, blood pressure $100 / 80 \mathrm{mmHg}$, and SaO2 $99 \%$ with nasal oxygenation. Cardiac examination showed a regular rate and rhythm with a diastolic murmur at left ICS III and upper left sternal border. Lower extremities showed pitting edema. Laboratory results: hemoglobin $9.6 \mathrm{~g} / \mathrm{dL}, \mathrm{RBC} 3.6 \times 106 / \mu \mathrm{L}$,

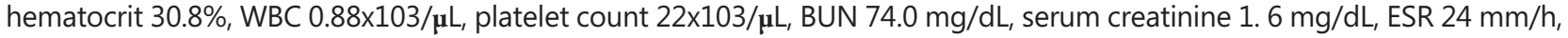
CRP $1.2 \mathrm{mg} / \mathrm{dL}, \mathrm{C} 3<16.4 \mathrm{mg} / \mathrm{dL}, \mathrm{C} 48 \mathrm{mg} / \mathrm{dL}$, ANA test indeterminate (23.84), and anti dsDNA negative (7.4 WHOunits/mL). Chest X-Ray showed mitral heart configuration with the right ventricle and left atrium enlargement, pneumonia, and right pleural effusion. ECG showed normal sinus rhythm, left ventricular hypertrophy with repolarization abnormality, and prolonged QT wave. A 2-D echocardiogram showed evidence of vegetation on the aortic and pulmonary valves. Based on the American College of Rheumatology SLE criteria, low complement level, and evidence of vegetation on the aortic and pulmonary valve, the patient was diagnosed as Libman-Sacks Endocarditis. The diagnosis should be confirmed by antiphospholipid antibodies examination.
\end{abstract}

Key words: Libman-Sacks endocarditis, systemic lupus erythematosus, complement level, valve vegetation

\section{INTRODUCTION}

Libman-Sacks endocarditis was first described by Emanuel Libman and Benjamin Sacks in 1924. ${ }^{1}$ It is also known as verrucous, marantic, or non-bacterial thrombotic endocarditis. The lesions primarily consist of accumulations of immune complexes and mononuclear cells. These subendothelial deposits may eventually lead to deformed valves. The most commonly involved valve is the mitral valve, followed by the aortic valve. Libman-Sacks lesions are associated with lupus duration, disease activity, anti-cardiolipin antibodies, and antiphospholipid syndrome. ${ }^{2}$

Heart valve abnormalities can be found in one of every three patients with Systemic Lupus Erythematosus (SLE), while valvular vegetations such as Libman-Sacks endocarditis, are present in 1 of every 10 SLE patients. ${ }^{3}$ Male lupus is rare, comprising $12 \%$ of patients with SLE. The diagnosis of Libman Sacks endocarditis becomes challenging, especially in differentiating it from infective endocarditis as both diseases may present similarly. ${ }^{4}$ The objective was to describe Libman-Sacks endocarditis in an SLE male patient.

\section{CASE}

A 21-year-old male was admitted to the hospital with shortness of breath, epigastric pain, oral ulcer, discoid lesions, and knee joints pain. This condition had been going on for three months. The patient worked as a paper mill employee two years ago. He was exposed to certain chemicals and instruments with UV rays.

The general status was weak. The vital signs examinations were as follows: GCS $4-5-6$, blood pressure 100/80 $\mathrm{mmHg}$, pulse rate 110 times/min, respiratory rate 30 times $/ \mathrm{min}$, temperature $37^{\circ} \mathrm{C}$, peripheral blood saturation $99 \%$ with nasal $\mathrm{O}^{2}$. Head and neck examination showed pale sclera and dyspnea. There was an oral ulcer on his lips and tongue. Discoid lesions were also found throughout the body. 


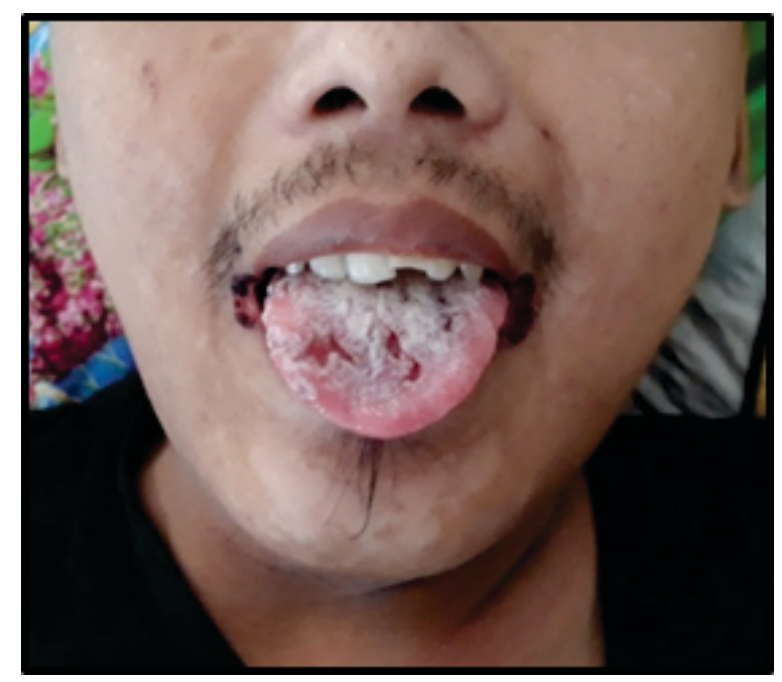

Figure 1. The presentation of oral ulcer and discoid lesions
Heart examination showed the single sound of S1 - S2 with a diastolic murmur at intercostal space III left to the parasternal line and upper left the sternal border. Lung examination showed vesicular sound without rhonchi and wheezing. An abdominal examination showed no abnormality. The extremities were warm on both sides, but there was pitting edema on lower extremities.

On the first day, the laboratory result showed a leukocytosis, slight anemia, and thrombocytopenia. Blood urea nitrogen and serum creatinine level were increased. Albumin level was decreased. The patient was diagnosed as infective endocarditis in the Department of Cardiology Vascular Medicine, Dr. Soetomo Hospital. Treatment was initiated with Ceftriaxone injection 1 gram twice per day and Levofloxacin injection $750 \mathrm{mg}$ once per day. He also received sodium bicarbonate drip, dopamine pump, and furosemide pump.

Table 1. Laboratory examination on the first admission day

\begin{tabular}{|c|c|c|c|c|c|}
\hline \multicolumn{3}{|c|}{ Hematology } & \multicolumn{3}{|c|}{ Clinical Chemistry } \\
\hline Parameters & Level & $\begin{array}{l}\text { Reference } \\
\text { range }\end{array}$ & Parameters & Level & $\begin{array}{l}\text { Reference } \\
\text { range }\end{array}$ \\
\hline WBC $\left(\times 10^{3} / \mu \mathrm{L}\right)$ & 12.24 & $3.37-10$ & BUN (mg/dL) & 49.0 & $7-18$ \\
\hline$\% \mathrm{Neu}$ & 79.80 & $39.8-70.5$ & $\mathrm{SCr}(\mathrm{mg} / \mathrm{dL})$ & 1.37 & $0.6-1.3$ \\
\hline \% Lym & 12.60 & $23.1-49.9$ & Alb (g/dL) & 2.76 & $3.4-5.0$ \\
\hline \% Mono & 5.50 & $4.3-10.0$ & $\mathrm{Na}(\mathrm{mmol} / \mathrm{L})$ & 133.0 & $136-145$ \\
\hline$\%$ Eos & 0.10 & $0.6-5.4$ & $\mathrm{~K}(\mathrm{mmol} / \mathrm{L})$ & 4.5 & $3.5-5.1$ \\
\hline$\%$ Baso & 0.40 & $0.3-1.4$ & $\mathrm{Cl}(\mathrm{mmol} / \mathrm{L})$ & 100.0 & $98-107$ \\
\hline $\mathrm{RBC} \times 10^{6} / \mu \mathrm{L}$ & 3.65 & $3.69-5.46$ & AST (U/L) & 99 & $0-50$ \\
\hline $\mathrm{Hb}(\mathrm{g} / \mathrm{dL})$ & 10.20 & $13.3-16.6$ & $\operatorname{ALT}(\mathrm{U} / \mathrm{L})$ & 31 & $0-50$ \\
\hline Hct (\%) & 35.30 & $41.3-52.1$ & \multicolumn{3}{|c|}{ Urinalysis } \\
\hline $\mathrm{MCV}(\mathrm{fL})$ & 96.60 & $86.7-102.3$ & Parameters & Level & $\begin{array}{c}\text { Reference } \\
\text { range }\end{array}$ \\
\hline $\mathrm{MCH}(p g)$ & 28.00 & $27.1-32.4$ & Glucose & Negative & Negative \\
\hline $\mathrm{MCHC}(\mathrm{g} / \mathrm{dL})$ & 28.90 & $29.7-33.1$ & Bilirubin & Negative & Negative \\
\hline RDW (\%) & 19.50 & $12.2-14.8$ & Keton & Negative & Negative \\
\hline Plt $\left(\times 10^{3} / \mu L\right)$ & 144.00 & $150-450$ & SG & 1,021 & $1,003-1,030$ \\
\hline \multicolumn{3}{|c|}{ Blood Gas Analysis } & Blood & $0-20$ & Negative \\
\hline Parameters & Level & $\begin{array}{c}\text { Reference } \\
\text { Range }\end{array}$ & $\mathrm{pH}$ & 5.0 & $4.5-8.0$ \\
\hline $\mathrm{pH}$ & 7.31 & $7.35-7.45$ & Protein & $1+$ & Negative \\
\hline $\mathrm{pCO}_{2}(\mathrm{mmHg})$ & 21.20 & $35-45$ & Urobilinogen & 1.0 & $<1.0$ \\
\hline $\mathrm{pO}_{2}(\mathrm{mmHg})$ & 65.40 & $80-100$ & Nitrit & Negative & Negative \\
\hline $\mathrm{HCO}_{3}(\mathrm{mmol} / \mathrm{L})$ & 10.70 & $22.0-26.0$ & Leukocytes & Trace & Negative \\
\hline $\mathrm{TCO}_{2}(\mathrm{mmol} / \mathrm{L})$ & 11.40 & $23-30$ & Color & $\begin{array}{c}\text { Dark } \\
\text { Yellow }\end{array}$ & Yellow \\
\hline $\mathrm{BE}$ & -15.70 & $2.5-3.5$ & Clarity & Cloudy & Clear \\
\hline $\mathrm{SO}_{2}(\%)$ & 90.80 & $94-98$ & \multicolumn{3}{|c|}{ Coagulation Study } \\
\hline $\mathrm{AaDO}_{2}$ & 54.70 & $0-100$ & Parameters & Level & $\begin{array}{c}\text { Reference } \\
\text { Range }\end{array}$ \\
\hline Temp & 37.00 & $36.0-37.0$ & PPT (s) & 17.8 & $9-12$ \\
\hline & & & APTT (s) & 33.1 & $22-33$ \\
\hline
\end{tabular}




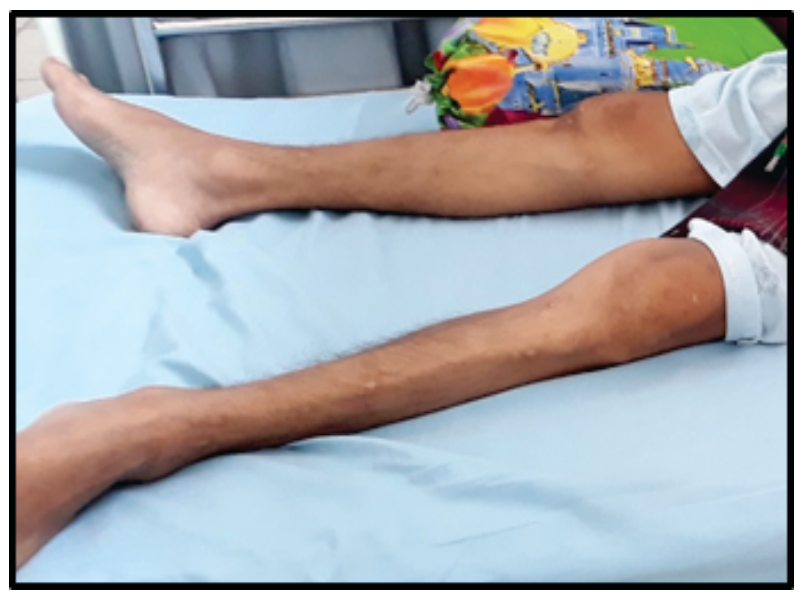

Figure 2. The presentation of knees swelling
On day 10, his clinical status continued to deteriorate. He felt his body getting weaker. Hemoglobin remained low, his platelets and white blood cells continued to drop extremely. Blood urea nitrogen and serum creatinine level were increased. Erythrocyte sedimentation rate was increased, so did CRP levels also increased. The Antinuclear Antibodies (ANA) test showed an indeterminate result. Complement component 3 (C3) level showed a very low result, as well as complement component 4 (C4) level also showed a low result. Patient was transferred to the Department of Internal Medicine Dr. Soetomo Hospital due to Libman-Sacks endocarditis caused by SLE.

Table 2. Laboratory examination on the tenth admission day

\begin{tabular}{|c|c|c|c|c|c|}
\hline \multicolumn{3}{|c|}{ Hematology } & \multicolumn{3}{|c|}{ Clinical Chemistry } \\
\hline Parameters & Level & $\begin{array}{l}\text { Reference } \\
\text { range }\end{array}$ & Parameters & Level & $\begin{array}{l}\text { Reference } \\
\text { range }\end{array}$ \\
\hline $\begin{array}{l}\text { WBC }(x \\
\left.10^{3} / \mu \mathrm{L}\right)\end{array}$ & 0.88 & $3.37-10$ & BUN (mg/dL) & 74.0 & $7-18$ \\
\hline$\% \mathrm{Neu}$ & 2.3 & $39.8-70.5$ & $\mathrm{SCr}(\mathrm{mg} / \mathrm{dL})$ & 1.6 & $0.6-1.3$ \\
\hline \% Lym & 47.7 & $23.1-49.9$ & Alb $(g / d L)$ & 3.4 & $3.4-5.0$ \\
\hline \% Mono & 50.0 & $4,3-10.0$ & $\mathrm{Na}(\mathrm{mmol} / \mathrm{L})$ & 131.0 & $136-145$ \\
\hline$\%$ Eos & 2.3 & $0.6-5.4$ & $\mathrm{~K}(\mathrm{mmol} / \mathrm{L})$ & 3.1 & $3.5-5.1$ \\
\hline$\%$ Baso & 0 & $0.3-1.4$ & $\mathrm{Cl}(\mathrm{mmol} / \mathrm{L})$ & 92.0 & $98-107$ \\
\hline $\mathrm{RBC} \times 10^{6} / \mu \mathrm{L}$ & 3.6 & $3,69-5,46$ & $\mathrm{Ca}(\mathrm{mmol} / \mathrm{L})$ & 7.1 & $8.5-10.1$ \\
\hline $\mathrm{Hb}(\mathrm{g} / \mathrm{dL})$ & 9.6 & $13.3-16.6$ & CRP (mg/L) & 1.2 & $0-1$ \\
\hline Hct $(\%)$ & 29.6 & $41.3-52.1$ & & Immunology & \\
\hline $\mathrm{MCV}(\mathrm{fL})$ & 82.9 & $86.7-102.3$ & Parameters & Level & $\begin{array}{c}\text { Reference } \\
\text { range }\end{array}$ \\
\hline $\mathrm{MCH}(p g)$ & 26.9 & $27.1-32.4$ & $\mathrm{HBsAg}$ & $\begin{array}{l}\text { Non- } \\
\text { Reactive }\end{array}$ & $\begin{array}{l}\text { Non-reactive: } \\
<0.99 \\
\text { Equivocal: } \\
1-50 \\
\text { Reactive: }>50\end{array}$ \\
\hline $\mathrm{MCHC}(\mathrm{g} / \mathrm{dL})$ & 32.4 & $29.7-33.1$ & ANA test & 23.84 & $\begin{array}{l}\text { Negative: }<20 \\
\text { Indeterminate: } \\
20-60 \\
\text { Positive: }>60\end{array}$ \\
\hline RDW (\%) & 19.0 & $12.2-14.8$ & C3 & $<16.4$ & $50-120$ \\
\hline Plt $\left(\times 10^{3} / \mu L\right)$ & 22 & $150-450$ & C4 & 8 & $20-50$ \\
\hline $\begin{array}{l}\text { ESR } \\
\text { (mm/hour) }\end{array}$ & 24 & $0-20$ & $\begin{array}{l}\text { Anti-dsDNA } \\
\text { (WHO units/mL) }\end{array}$ & Negative & $\begin{array}{l}\text { Negative: } \\
0-92.6 \\
\text { Equivocal: } \\
92.7-138,9 \\
\text { Moderate } \\
\text { Positive: } \\
139-370,4 \\
\text { Strong } \\
\text { Positive: } 370,5\end{array}$ \\
\hline
\end{tabular}




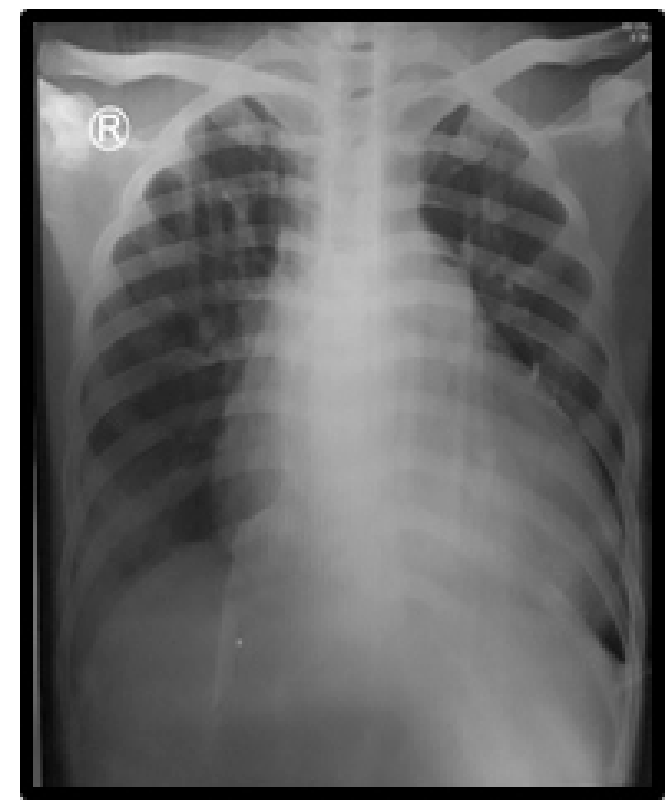

Figure 3. Chest X-Ray showed right ventricle and left atrium enlargement

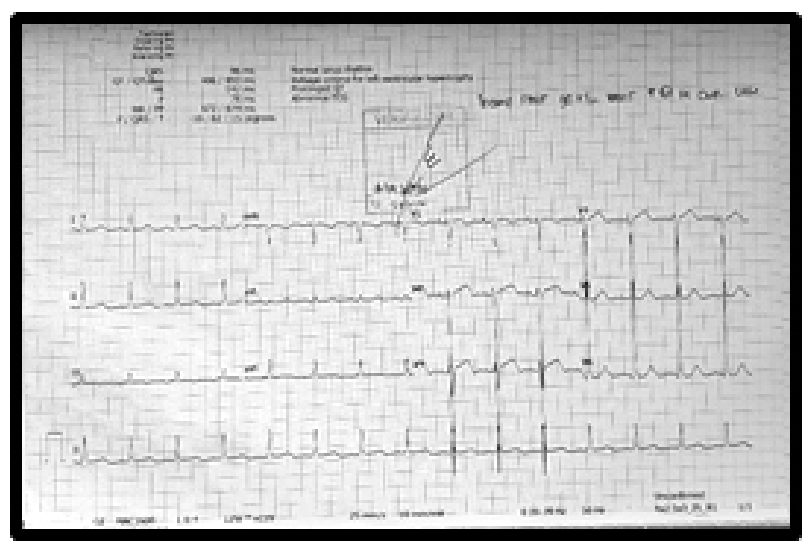

Figure 4. ECG showed left ventricular hypertrophy and prolonged QT wave

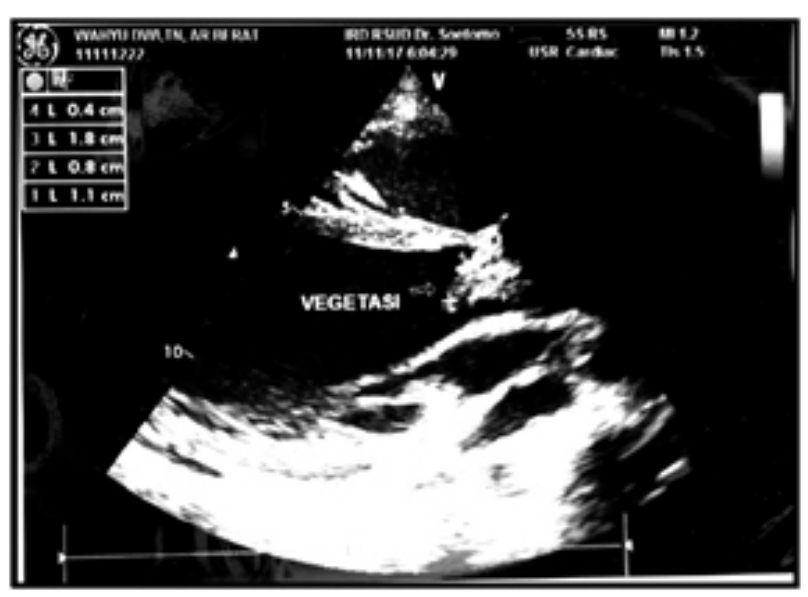

Figure 5. Echocardiogram showed vegetation on aortic and pulmonary valve
Blood cultures on three sites were done. The two specimens showed Granulicatella adiacens growth and one specimen showed Acinetobacter spp. growth. Urine culture showed Klebsiella pneumonia growth 1 x 104 CFU/mL without any symptom in the urinary tract. Thus, this was a probable absence of infection.

Chest X-Ray showed mitral heart configuration with the right ventricle and left atrium enlargement, pneumonia, and right pleural effusion. An electrocardiogram showed normal sinus rhythm, left ventricular hypertrophy with repolarization abnormality, and prolonged QT wave. A 2-D echocardiogram showed evidence of vegetation on the aortic and pulmonary valves.

Due to the patient having fulfilled possible Libman-Sacks endocarditis by American College of Rheumatology SLE criteria, he was given a regimen of methylprednisolone injection. Clinical improvement was noted during the hospital stay with the completion of steroids. The patient was successfully treated and recovered. On day 20, he went home in good condition.

\section{DISCUSSION}

Systemic lupus erythematosus is an Immune Complex (IC) mediated disease, which can affect any organ. Clinical presentations are protean, and patients may present to virtually any medical specialty. Systemic lupus erythematosus affects up to $1: 1000$ of the population, being more common in females than males (9:1). Incidence peaks in the second/third decades as well as in later life. Systemic lupus erythematosus is an IC deposition disease, where inflammation and ultimately organ dysfunction are due to deposition of ICs in the vasculature of the affected organs. ${ }^{5}$ DNA damage and apoptosis of keratinocytes is induced by Ultraviolet (UV) light. Apoptosis and UV light have also been involved in nuclear antigens translocation to surface blebs and with increased plasmacytoid dendritic cells and $T$ cells chemotaxis to skin lesions, with ensuing pro-inflammatory cytokines (IL-1, IL-10, IFN- $\gamma$, TNF- $\alpha$ ) production. ${ }^{6}$

In 1924, Libman and Sacks originally described valvular lesions in 4 patients with lupus and added non-rheumatic verrucous endocarditis to the syndrome complex of SLE. Libman-Sacks valvular lesions are sterile fibrofibrinous vegetations that favor the left-sided heart valves and usually form on the ventricular surface of the mitral valve. The disease progresses from a variable extent of inflammation 
along with fibrin deposits acutely to end-stage or healed forms with a fibrous plaque. The pathogenesis is thought to involve the formation of fibrin-platelet thrombi, which organizes and leads to fibrosis and scarring with subsequent valve dysfunction. ${ }^{7}$

Systemic lupus erythematosus is diagnosed based on both clinical and laboratory features. The Systemic Lupus International Collaborating Clinics (SLICC) has developed classification criteria for lupus, used as an aid in the diagnosis of this complex multi-organ system disease. The presence of at least 4 of the 11 clinical criteria and 1 laboratory criteria yields a sensitivity of $85 \%$ and a specificity of $95 \%$ for SLE. ${ }^{6}$

Complement plays a dual role in SLE. There is a strong association of genetic deficiencies of $\mathrm{C} 1, \mathrm{C} 4$, $C 2$, and C3 with SLE, indicating a protective role. Three complement-dependent mechanisms have been proposed: (1) complement-dependent clearance of immune complexes; (2) an essential role for complement in the development and maintenance of self-tolerance in B lymphocytes; and (3) a requirement for complement in the clearance of apoptotic cells and potential autoantigens released from such cells. On the other hand, complement activation is believed to play a pathogenic role in tissue damage induced by autoantibodies in SLE. ${ }^{8}$

Complement level in this patient showed a low level of $\mathrm{C} 3$. Factors $\mathrm{H}$ and $\mathrm{I}$ are required to control the fluid-phase alternative-pathway C3 convertase. Complete deficiency of either protein results in $\mathrm{C} 3$ cleavage and depletion to very low levels. C5, factor $B$, and properdin levels may also be reduced. The clinical presentation of patients with factor $\mathrm{H}$ or factor I deficiency resembles that of primary C3 deficiency. The highest disease association is an increased incidence of SLE. ${ }^{8}$

The level of complement $C 4$ was also low in this patient. There are two $\mathrm{C} 4$ genes, $\mathrm{C} 4 \mathrm{~A}$ and $\mathrm{C} 4 \mathrm{~B}$, located within the Major Histocompatibility Complex (MHC) on chromosome 5. The two forms of $\mathrm{C} 4$ have a similar function, but different substrate preferences for the covalent bonding reaction that occurs on activation to C4b. C4A is more efficient in attaching to amino groups on proteins, such as immune complexes, whereas $C 4 B$ is more efficient in attaching to carbohydrates. Complete $\mathrm{C} 4$ deficiency requires four null alleles and is rarely found, but is highly associated with SLE (75\% incidence). Partial C4 deficiencies with one to three null alleles, however, are relatively common, found in up to $25 \%$ of individuals. Complete C4A deficiency is greatly overrepresented in the SLE population. C4A deficiencies are found in about $1 \%$ of the general population and $10-15 \%$ of patients with SLE. Complete C4B deficiencies are more commonly associated with bacterial infections, suggesting that the functionally different C4 genes contribute differently to host defense and autoimmunity. ${ }^{8}$

Antinuclear Antibodies (ANA) are found in more than $98 \%$ of SLE patients. Most lupus autoantibodies bind to the nuclear antigens, although some bindto the plasma proteins, extracellular matrix antigens, and cell membrane antigens. Their presence is not specific to SLE because they are also present in other autoimmune disorders (e.g., scleroderma, Sjögrens's

Table 3. SLE criteria from Systemic Lupus International Collaborating Clinics (SLICC) 2012 found in patient6

Requirements: $\geq 4$ criteria (at least 1 clinical and 1 laboratory criteria)

OR biopsy-proven lupus nephritis with positive ANA or Anti-DNA

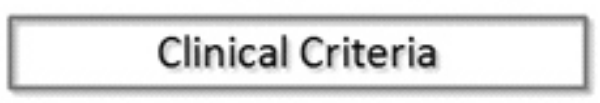

1. Acute Cutaneous Lupus*

2. Chronic Cutaneous Lupus*

3. Oral or nasal ulcers*

4. Non-scarring alopecia

5. Arthritis *

6. Serositis *

7. Renal *

8. Neurologic *

9. Hemolytic anemia

10. Leukopenia *

11. Thrombocytopenia $\left(<100,000 / \mathrm{mm}^{3}\right)$

† SLICC: Systemic Lupus Intemational Collaborating Clinics

- See notes for criteria details

\section{Immunologic Criteria}

\author{
1. ANA \\ 2.Anti-DNA \\ 3. Anti-Sm \\ 4. Antiphospholipid $\mathrm{Ab}$ * \\ 5. Low complement ( $\mathrm{C} 3, \mathrm{C} 4, \mathrm{CH} 50)$ \\ 6. Direct Coombs' test (do not count in \\ the presence of hemolytic anemia)
}


disease, rheumatoid arthritis), malignancies, infections including parasitic (malaria) and viral (hepatitis) as well as in response to therapeutic agents as environmental triggers. Antinuclear antibodies are typically examined by their binding to Hep-2 cells. Common ANA specificities found in SLE patients include ssDNA, dsDNA, extractable nuclear antigens (such as Sm Ro, RNP, and La), chromatin, and histones. Specific ANA contributes to disease subsets such as anti-Ro antibodies with subacute cutaneous and neonatal SLE and anti-dsDNA antibodies with renal disease. The most autoantibodies histones do not correlate with activity of the disease; anti-dsDNA antibodies are a notable exception, fluctuating with disease activity, thereby suggesting a pathogenic role for this autoantibody in the pathogenesis of the disease. ${ }^{6}$

The antinuclear antibodies test in this patient showed an indeterminate result. It can be caused by the different methods used to examine the level of the patient. Antinuclear antibodies test is measured by ELISA in our hospital. The advantages of ELISA testing include the speed and simplicity of the assay. Disadvantages of ELISA testing include reduced antigen diversity leading to a decreased sensitivity for the identification of antinuclear antibodies, and reduced ability to assess the quality of the antigen preparation by direct inspection of results of the assay compared to immunofluorescence. When performed in a proficient laboratory, immunofluorescence is a highly sensitive assay for the presence of antinuclear antibodies. $^{9}$

Anti-dsDNA done after the patient received treatment of SLE was negative. The decrease in anti-dsDNA at the time of the flare is not likely to be clinically useful. First, most SLE patients will not be seen monthly. Second, the cost of monthly anti-dsDNA assays is difficult to justify, since the flares can be detected clinically or by routine laboratory testing during the same visit. Third, the pattern of decrease in anti-dsDNA with flares is not universal. Some flares occur with no change in anti-dsDNA or with an increase. Changes in anti-dsDNA occurring without clinical signs of activity should not be treated presumptively. ${ }^{10}$

These laboratory findings, coupled with the patient's multiple negative blood cultures and lack of response to antibiotics led us to the correct diagnosis of Libman-Sacks endocarditis in this patient. In addition to the laboratory testing that was undertaken, there was found that serial echocardiograms allowed good visualization of the mitral valve to assess disease progression and resolution of the vegetations caused by Libman-Sacks endocarditis.

Antiphospholipid antibodies are found in $50 \%$ of lupus patients and thrombotic events occur in about half of these patients. Antiphospholipid antibodies found in patients without SLE have similar clinical consequences. The disease pathogenesis has been attributed to the procoagulant effects of antiphospholipid antibodies. Laboratory tests that have to be done to assess for the presence of this syndrome are lupus anticoagulant, anti-Cardiolipin $\lg \mathrm{G}, \lg \mathrm{A}$, IgM, and beta-2-Glycoprotein I antibodies. ${ }^{8}$ It helps to provide an additional mechanism of injury to the cardiac valve as seen in Libman-Sacks endocarditis.

\section{CONCLUSION}

Based on the American College of Rheumatology SLE criteria, low complement level, and evidence of vegetation on the aortic and pulmonary valve, the patient was diagnosed as Libman-Sacks Endocarditis. The diagnosis should be confirmed by antiphospholipid antibodies examination, which may have an impact on the SLE presentation, management, and prognosis.

\section{REFERENCES}

1. Libman E, Sacks BA. Undescribed form of valvular and mural endocarditis. Arch Intern Med, 1924; 33: 701-737.

2. Moyssakis I, Tektonidou MG, Vassilliou VA, Samarkos $M$, Votteas $V$, et al. Libman-Sacks endocarditis in systemic lupus erythematosus: Prevalence, associations, and evolution. Am J Med, 2007; 120: 636-42.

3. Ruiz-Irastorza G, Khamashta M. Cardiopulmonary disease in SLE. Dubois' lupus erythematosus and related syndromes. $8^{\text {th }}$ Ed., California, Elsevier Inc, 2012; 352-362.

4. Salvador MT, Navarra SV. Infective versus Libman Sacks Endocarditis in systemic lupus erythematosus. Rheumatol Curr Res, 2013; S16.

5. Keogan MT, Wallace EM, O'Leary P. Connective tissue disease in concise clinical immunology for healthcare professionals. New York, USA, Routledge, 2006; 211.

6. Aranow C, Diamond B, Mackay M. Systemic lupus erythematosus in clinical immunology: Principle and practice. Third Ed., China, Elsevier, 2008; 749-766.

7. Menard GE. Establishing the diagnosis of Libman-Sacks Endocarditis in systemic lupus erythematosus. J Gen Intern Med, 2008, 23(6): 883-6.

8. Du Clos TW, Mold C. Complement and complement deficiencies in clinical immunology: Principle and practice. Third Ed., China, Elsevier, 2008; 305-326.

9. Greidinger EL, Hoffman RW. Antinuclear antibody 
testing: Methods, indications, and interpretation. Laboratory Medicine, 2003; 34(2): 113-117.

10. Ho A, Magder LS, Barr SG, Petri M. Decreases in anti-double-stranded DNA levels are associated with concurrent flares in patients with systemic lupus erythematosus. Arthritis and Rheumatology, 2001; 44(10): $2342-2349$. 